\title{
COOPERATIVE ADAPTIVE CRUISE CONTROL: CRITICAL HUMAN FACTORS ISSUES AND RESEARCH QUESTIONS
}

\author{
Stephen Jones ${ }^{1}$ \& Brian H. Philips ${ }^{2}$ \\ ${ }^{1}$ SAIC, McLean, Virginia, USA \\ ${ }^{2}$ Federal Highway Administration, McLean, Virginia, USA \\ Email: stephen.m.jones@saic.com
}

\begin{abstract}
Summary: As traffic volume and delay on highways increase each year, new solutions are required to meet travel demand and ease congestion. One possible solution, Cooperative Adaptive Cruise Control, permits vehicles and infrastructure to communicate, providing the capability to maintain safety while increasing travel lane capacity. The technical capabilities have been demonstrated, but as important to ensuring successful implementation is an understanding of the potential human factors-related issues. Use of automation in the driving environment can have numerous pitfalls, which are heavily influenced by a variety of both deliberate and reflexive human judgments and decisions known to be error-prone. This paper examines these potential issues and identifies research areas and questions that may guide future research to evaluate the safety, efficacy, and acceptance of this new technology.
\end{abstract}

\section{INTRODUCTION}

Delay on the Nation's highway systems is a major cost to motorists and businesses - over $\$ 100$ billion in lost time and wasted fuel in 2010 for urban areas (Schrank, Lomax, \& Eisel, 2011). Congestion has steadily worsened because the population of drivers, number of vehicles, and travel volume continue to increase at a faster rate than system capacity. For many drivers in urban areas, severe commute congestion is experienced daily. In 1982, the annual average delay per commuter was 14 hours; it climbed to 34 hours in 2010 and is forecasted to increase to 41 hours by 2020 (Schrank et al., 2011).

The use of highly integrated Intelligent Transportation Systems (ITS), such as electronic information and communication technology, may help extend the capacity of the existing infrastructure system and address the problem of recurring congestion and reduced mobility. One proposed ITS technology, Cooperative Adaptive Cruise Control (CACC), has the potential to improve traffic flow and reduce bottlenecks. This CACC technology promises to increase traffic throughput without requiring additional lane development. Dedicated shortwave radio communications directly between equipped vehicles and roadway infrastructure better inform drivers of the surrounding driving environment and automate throttle and brake activation, permitting vehicles to travel more closely together. Micro-simulations evaluating CACC usage have shown that once the technology penetration rate exceeds about 40\% (Arnaout \& Bowling, 2011; Shladover, Su, \& Lu, 2012; van Arem, van Driel, \& Visser, 2006), throughput quickly increases to $193 \%$ of pre-CACC levels and approaches 4250 vehicle hours per lane at $60 \mathrm{mph}$ and 100\% usage (Ryus, Vandehey, Elefteriadou, Dowling, \& Ostrom, 2011).

Because vehicle-to-vehicle data broadcasts permit CACC vehicles to monitor and react to vehicles further downstream than just the immediately preceding vehicle, speed adjustments are 
made more quickly and string stability benefits are also realized. Infrastructure-to-vehicle broadcasts also promote stability by being able to warn drivers and/or directly influence a vehicle's speed due to downstream disturbances not yet evident to a driver, such as a reduction in average speed, accident, or lane closures. In addition, using broadcasted traffic signal phase and timing information, CACC could influence approaches to red light intersections to reduce delays, emissions, and fuel consumption.

Although already demonstrated as technically feasible, CACC faces many potential hurdles related to the abilities and limitations of the humans using the system. These human factorsrelated issues may impact the success of a new system and need to be addressed before implementation can be considered. Application, use, reliance, and trust of automation have numerous pitfalls, all exacerbated when applied to dynamic and fast-pace environments such as highway travel. Additionally, the effect CACC usage may have on a driver's workload directly impacts driving performance and also influences one's overall situation awareness. CACC system success also relies on an accurate understanding of general driving behavior, such as vehicle following, lane position variability, and lane changing. Each of these is heavily influenced by a variety of both deliberate and reflexive human judgments, which are prone to errors and misguided decisions.

This paper highlights the critical aspects of these human factors issues and identifies key research questions that can serve as a foundation for future research to evaluate the safety, efficacy, and acceptance of CACC technology.

\section{HUMAN FACTORS-RELATED ISSUES}

\section{Automation}

The primary benefit of CACC technology is the automated reaction to changing velocities on the roads, with brake reaction times (BRTs) significantly shorter than those of humans. Even the shortest of human BRTs, those of young athletes, fall in the .47-.55s range, and reaction times increase as people age (Schweitzer, Apter, Ben-David, Liebermann, \& Parush, 1995; TaiebMaimon \& Shinar, 2001). With CACC technology, BRTs occur in less than .1s (Maciuca \& Hedrick, 1995); automation, therefore, provides a distinct improvement over human capabilities. However, automation's success relies not only on its technical abilities, but also on peoples' willingness to use, application of, and reliance on the automation.

Willingness to utilize automation is often based upon the trust one places on the automation. Trust typically evolves over time in complex individual, cultural, societal, and organizational contexts and is usually based upon a technology's perceived ability to achieve a particular goal (Lee \& See, 2004). However, this trust is not always awarded appropriately. The correct level of trust depends upon an accurate understanding of the automation's purpose, how it operates, and its historical performance (Lee \& Moray, 1992). Incorrect levels of trust lead to misuse, disuse, and abuse of that automation (Parasuraman \& Riley, 1997).

The application of automation also changes the nature of the role of the human, placing them into more of a monitoring role. Numerous studies and real-world examples have demonstrated catastrophic results from poor monitoring skills (Federal Aviation Administration, 1990; 
National Transportation Safety Board, 1997; Riley, 1994; Young \& Stanton, 2001), and many of them stem from a lack of understanding of the automation's abilities, how to correctly use it, and over-reliance on the technology. Because CACC permits car following at distances far shorter than would be recommended under manual control, any unexpected failure of the automation puts the driver in a significantly disadvantaged and least capable position (Bainbridge, 1983; Parasuraman \& Riley, 1997), possibly requiring driver action beyond what time or following distance may allow.

\section{Key Research Questions}

One of the primary concerns about this technology pertains to acceptance and appropriate use by the intended audience. CACC provides greatest benefit in dense traffic in highway environments, allowing more vehicles to travel in a given lane. However, it is possible that drivers may not trust CACC in such situations, eliminating its benefits (McDonald, Marsden, and Brackstone, 2001).

- How does traffic density affect choice to utilize CACC?

- Does the number of travel lanes affect choice to utilize CACC?

- Do available preset time gap options affect CACC utilization?

\section{Workload, Distraction, and Situation Awareness}

Automation is typically introduced to reduce one's workload, and in driving environments, the intent is to permit additional resources to be used for other driving-related activities, such as hazard identification and prediction (Stanton \& Marsden, 1996). Previous studies of adaptive cruise control (ACC) have reflected reduced workload levels (Ma, 2005; Stanton \& Young, 2005), so it would be reasonable to assume CACC should show the same pattern. However, the Yerkes-Dodson Law professes that human performance is optimal somewhere in between workload extremes (Wickens \& Hollands, 2000). Reducing a driver's workload too much can stunt arousal levels and lead to performance decrements.

With a portion of the driving task aided by automation, the driver has the ability to put the freedup attention resources towards improving surveillance performance or other driving-related tasks. Numerous studies regarding driving automation, including ACC, have demonstrated that, unfortunately, this spare capacity is often used to engage in non-driving-related secondary tasks and increased off-road glances (Cho, Nam, \& Lee, 2006; Fancher et al, 1998; Jamson, Merat, Carsten, \& Lai, 2011).

Increased secondary task engagement has a direct impact on a driver's situation awareness (SA), decreasing one's ability to react to an unexpected conflict or system malfunction. Several studies on BRTs with automation clearly demonstrate the potentially disastrous effects distraction and lowered SA levels can promote; under automated driving, braking occurred later and at significantly higher rates (Merat \& Jamson, 2009; Young \& Stanton, 2007). These data indicate that rather than maintaining the necessary SA for conflict identification, drivers tend to over-rely on automation and point their attention to non-driving related tasks. With closer following gaps, CACC usage may not permit adequate time for a driver to recover from failed SA maintenance. 


\section{Key Research Questions}

- How does use of CACC affect workload and SA levels?

- Are drivers more likely to engage in secondary tasks while utilizing CACC?

- Does driving performance change during CACC driving? During secondary tasks?

\section{Driving Behavior}

In addition to being required for accurate microscopic simulation modeling, an understanding of general driver behavior is necessary to determine areas in which automation such as CACC may pose risks or issues. Driving behavior study typically involves areas such as lane-changing, carfollowing, turning, acceleration, and deceleration; of particular concern for CACC technology is lane-changing and car following. Although these actions are directly measurable, the motivating forces behind them are more difficult to ascertain and may be prone to human error.

Throughput benefits from CACC can only be realized by platoons of enabled cars allowing the technology to safely guide them at reduced following gaps. Inaccurate human perception, however, may inadvertently prevent this. Studies on lane-changing have indicated that drivers tend to pass lead vehicles even when that vehicle is traveling faster than the driver's average speed (Bar-Gera \& Shinar, 2005). Additionally, studies have shown humans are not good at assessing the comparative average speeds of travel lanes, often mistakenly believing adjacent lanes are moving faster than their own even when they are no faster or even slower (Redelmeier \& Tibshirani, 2000). These tendencies may point to CACC drivers resisting the need to stay in a CACC platoon to maintain string stability and improve throughput efficiency.

Inaccurate perception may also factor heavily into following gap comfort. Research has shown drivers to be relatively accurate when judging distance to a preceding vehicle but poor when judging time (de Vos, Theeuwes, Hoekstra, \& Coemet, 1997; Taieb-Maimon \& Shinar, 2001). Furthermore, some studies have shown drivers to follow larger vehicles at shorter gaps even though visibility is reduced (Brackstone, Waterson, \& McDonald, 2009; Sayer, Mefford, \& Huang, 2000).

Numerous studies have assessed a driver's comfort with following a lead vehicle at various gaps, regardless of whether they are driving manually or with some variety of automation, including CACC. However, an important aspect that has yet to be researched is how comfortable a driver would be having another vehicle following that close to their car. The gaps utilized with CACC would likely be considered tailgating in normal, manual driving conditions, which means drivers may be less accepting of others driving at close distances, especially if they are not certain the following vehicle is under automated control. Studies showing people typically overestimating their own skills and underestimating those of others would hint at reduced comfort with succeeding vehicles (Kruger \& Dunning, 1999). As drivers become more comfortable with the technology, their comfort levels for those behind them may increase, though.

\section{Key Research Questions}

- How comfortable is a driver with a following vehicle at a short time gap? 
- Does comfort level change after experience with a CACC vehicle, if the driver is the lead vehicle of a platoon, or as density of surrounding traffic changes?

- How willing are drivers to remain in a CACC platoon as adjacent lane conditions vary?

\section{CONCLUSIONS}

New ITS technologies show significant promise to reduce the increasing delays on today's highways. Cooperative adaptive cruise control provides the ability for vehicles to travel safely at reduced time gaps to increase a travel lane's throughput and efficiency. The success of this system, however, does not lie in its technical capabilities but, rather, in the human factors-related issues that may affect how, when, and if it is utilized. Some research has been completed to show CACC's viability, but more is necessary before it can be considered for introduction to consumer and commercial vehicles.

This paper highlights some of the important human factors areas and key research questions that need to be addressed, such as how automation like CACC affects drivers' workload, situation awareness, and comfort levels. Additionally, existing research on general driving behavior highlights human limitations in perception and judgment that may undermine CACC's potential. A more thorough exploration of these issues can be found in a recent technical report on which this paper is based (see Jones, in press). The research areas and questions presented in this paper provide a good foundation to assist researchers in this domain to explore these key issues and provide a solid footing for this new technology to emerge.

\section{ACKNOWLEDGEMENTS}

Work described in this paper was performed under Contract Number DTFH61-08-C-00006 with the Federal Highway Administration, U.S. Department of Transportation. Authors acknowledge the guidance and support provided by the Office of Operations R\&D.

\section{REFERENCES}

Arnaout, G. and Bowling, S. (2011). "Towards Reducing Traffic Congestion Using Cooperative Adaptive Cruise Control on a Freeway with a Ramp.” Journal of Industrial Engineering and Management, Vol. 4, No. 4, pp. 699-717, Omnia Science, Terrassa, Spain.

Bainbridge, L. (1983). “Ironies of Automation.” Automatica, Vol. 19, No. 6, pp. 775-779, Pergamon, Oxford, UK.

Bar-Gera, H. and Shinar, D. (2005). “The Tendency of Drivers to Pass Other Vehicles.” Transportation Research Part F: Traffic Psychology and Behaviour, Vol. 8, No. 6, pp. 429-439, Elsevier, Amsterdam, Netherlands.

Brackstone, M., Waterson, B., and McDonald, M. (2009). "Determinants of Following Headway in Congested Traffic.” Transportation Research Part F: Traffic Psychology and Behaviour, Vol. 12, No. 2, pp. 131-142, Elsevier, Netherlands.

Cho, J.H., Nam, H.K., and Lee, W.S. (2006). “Driver Behaviour with Adaptive Cruise Control.” International Journal of Automotive Technology, Vol. 7, No. 5, pp. 603-608, Korean Society 
of Automotive Engineers, Seoul, Korea.

de Vos, A.P., Theeuwes, J., Hoekstra, W., and Coëmet, M.J. (1997). "Behavioral Aspects of Automatic Vehicle Guidance: Relationship Between Headway and Driver Comfort.” Transportation Research Record 1573, pp. 17-22, Transportation Research Board, Washington, DC.

Fancher, P., Ervin, R., Sayer, J., Hagan, M., Bogard, S., Bareket, Z., Mefford, M., and Haugen, J. (1998). Intelligent Cruise Control Field Operational Test, Report No. DOT-HS-808-849, National Highway Traffic Safety Administration, Washington, DC.

Federal Aviation Administration (1990). The National Plan for Aviation Human Factors, Washington, DC.

Jamson, H., Merat, N., Carsten, O., and Lai, F. (2011). "Fully-Automated Driving: The Road to Future Vehicles.” Proceedings of the Sixth International Driving Symposium on Human Factors in Driver Assessment, Training, and Vehicle Design, University of Iowa, Iowa City, IA.

Jones, S. (in press), Cooperative Adaptive Cruise Control: Human Factors Analysis, FHWA report number HRT-13-045, pp. 1 - 34, Department of Transportation, Washington, D.C.

Kruger, J. and Dunning, D. (1999). "Unskilled and Unaware of It: How Difficulties in Recognizing One’s Own Incompetence Lead to Inflated Self-Assessments.” Journal of Personality and Social Psychology, Vol. 77, No. 6, pp. 1,121-1,134, American Psychological Association, Washington, DC.

Lee, J. and Moray, N. (1992). “Trust, Control Strategies and Allocation of Function in HumanMachine Systems.” Ergonomics, Vol. 35, No. 10, pp. 1,243-1,270, Taylor \& Francis, New York, NY.

Lee, J.D. and See, K.A. (2004). "Trust in Automation: Designing for Appropriate Reliance.” Human Factors, Vol. 46, No. 1, pp. 50-80, Human Factors and Ergonomics Society, Santa Monica, CA.

Ma, R. (2005). The Effect of In-Vehicle Automation and Reliability on Driver Situation Awareness and Trust, Ph.D. dissertation, North Carolina State University, Raleigh, NC.

Maciuca, D.B. and Hedrick, J.K. (1995). "Brake Dynamics Effect on AHS Lane Capacity.” Systems and Issues in ITS, pp. 81-86, National Highway Traffic Safety Administration, Washington, DC.

McDonald, M., Marsden, G., and Brackstone, M. (2001). "Deployment of Interurban ATT Test Scenarios (DIATS): Implications for the European Road Network.” Transport Reviews, Vol. 21, No. 3, pp. 303-335, Taylor \& Francis, New York, NY.

Merat, N. and Jamson, A.H. (2009). “How Do Drivers Behave in a Highly Automated Car?” Proceedings of the Fifth International Driving Symposium on Human Factors in Driver Assessment, Training, and Vehicle Design, University of Iowa, Iowa City, IA.

National Transportation Safety Board (1997). Grounding of the Panamanian Passenger Ship Royal Majesty on Rose and Crown Shoal Near Nantucket, Massachusetts, June 10, 1995, Washington, DC.

Parasuraman, R. and Riley, V. (1997). Humans and Automation: Use, Misuse, Disuse, Abuse. 
Human Factors: The Journal of the Human Factors and Ergonomics Society, 39(2), 230253.

Redelmeier, D. and Tibshirani, R. (2000). “Are Those Other Drivers Really Going Faster?” Chance, Vol. 13, No. 3, pp. 8-14, Springer, Heidelberg, Germany.

Riley, V. (1994). “A Theory of Operator Reliance on Automation.” Human Performance in Automated Systems: Recent Research and Trends, pp. 19-35, Erlbaum, Hillsdale, NJ.

Ryus, P., Vandehey, M., Elefteriadou, L., Dowling, R.G., and Ostrom, B.K. (2011). "Highway Capacity Manual 2010.” TR News 273, pp. 45-48, Transportation Research Board, Washington, DC.

Sayer, J.R., Mefford, M.L. and Huang, R. (2000). The Effect of Lead-Vehicle Size on Driver Following Behavior, University of Michigan Transportation Research Institute, Ann Arbor, MI.

Schrank, D., Lomax, T., and Eisel, B. (2011). 2011 Urban Mobility Report, Texas Transportation Institute, Texas A\&M University System, College Station, TX.

Schweitzer, N., Apter, Y., Ben-David, G., Liebermann, D.G., and Parush, A. (1995). “A Field Study on Braking Responses During Driving. II. Minimum Driver Braking Times.” Ergonomics, Vol. 38, No. 9, pp. 1,903-1,910, Taylor \& Francis, New York, NY.

Shladover, S. E., Su, D., and Lu, X. Y. (2012). "Impacts of Cooperative Adaptive Cruise Control on Freeway Traffic Flow.” Transportation Research Board 91 ${ }^{\text {st }}$ Annual Meeting (No. 121868).

Stanton, N.A. and Marsden, P. (1996). "From Fly-by-Wire to Drive-by-Wire: Safety Implications of Automation in Vehicles.” Safety Science, Vol. 24, No. 1, pp. 35-49, Elsevier, Amsterdam, Netherlands.

Stanton, N.A., Young, M., and McCaulder, B. (1997). "Drive-by-Wire: The Case of Driver Workload and Reclaiming Control with Adaptive Cruise Control.” Safety Science, Vol. 27, Nos. 2-3, pp. 149-159, Elsevier, Amsterdam, Netherlands.

Taieb-Maimon, M. and Shinar, D. (2001). "Minimum and Comfortable Driving Headways: Reality Versus Perception.” Human Factors, Vol. 43, No. 1, pp. 159-172, Human Factors and Ergonomics Society, Santa Monica, CA.

van Arem, B., van Driel, C.J.G., and Visser, R. (2006). "The Impact of Cooperative Adaptive Cruise Control on Traffic-Flow Characteristics.” IEEE Transactions on Intelligent Transportation Systems, Vol. 7, No. 4., pp. 429-436, Intelligent Transportation Systems Society.

Wickens, C.D. and Hollands, J.G. (2000). Engineering Psychology and Human Performance, Third Edition, Pearson, Upper Saddle River, NJ.

Young, M.S. and Stanton. N.A. (2001). "Size Matters: The Role of Attentional Capacity in Explaining the Effects of Mental Underload in Performance.” Engineering Psychology and Cognitive Ergonomics Volume 5: Aerospace and Transportation Systems, D. Harris (ed.), Ashgate Publishing, Surrey, UK.

Young, M.S. and Stanton, N.A. (2007). "Back to the Future: Brake Reaction Times for Manual and Automated Vehicles.” Ergonomics, Vol. 50, No. 1, pp. 46-58, Taylor \& Francis, New York, NY. 